\title{
ENSINO DE PORTUGUÊS PARA NATIVOS E ESTRANGEIROS: NA PRÁTICA, A TEORIA É OUTRA
}

Maria Helena da Nóbrega*

\begin{abstract}
Resumo: Este artigo apresenta diferentes momentos do ensino de língua portuguesa para nativos e estrangeiros, procurando pontos de contato entre ambos. Esse percurso metodológico destaca noções ligadas ao sistema e ao uso da língua, além de explicar os métodos da gramática e tradução, o audiolingual e, com maior ênfase, a abordagem comunicativa. A análise dessas formas de ensino revela a centralização ainda vigente em propostas gramaticalistas, apesar de as investigações teóricas já terem questionado esse tipo de abordagem. Após refletir sobre as causas do pouco aproveitamento das pesquisas na sala de aula, propõem-se maneiras de reverter a distância observada entre os avanços teóricos e a prática pedagógica.
\end{abstract}

Palavras-chave: português; língua materna e estrangeira; ensino

Introdução

O ensino do português pode ocorrer com diferentes especificidades: no nível fundamental, médio e superior, para falantes nativos ou estrangeiros. Embora em todos os casos o foco seja a língua portuguesa, Saussure (2006) já esclareceu que o ponto de vista recria o objeto. Portanto, nessas diversas situações formais, a língua comparecerá à aula de uma maneira particular, conforme as finalidades em questão.

No âmbito deste trabalho, analiso o ensino de português língua materna (PLM) e português língua estrangeira (PLE), buscando identificar diálogos possíveis entre esses dois campos de estudo, de forma que, nos contatos fronteiriços, ambos possam se beneficiar das pesquisas já realizadas.

A delimitação em PLM e PLE deve-se à importância que ambos vêm recebendo na atualidade. O SAEB (Sistema de Avaliação da Educação Básica) e o ENEM (Exame Nacional do Ensino Médio) são dois exemplos de aferição dos conhecimentos dos alunos, fortemente focados na língua portuguesa. Além disso, a nota da redação também é fator decisivo na aprovação do vestibular, cuja seleção é bastante calcada em questões de produção e compreensão de textos.

No tocante a PLE, a expansão tem ocorrido de forma vertiginosa. Basta dizer que há cursos de PLE em instituições do ensino superior nos cinco continentes. No Brasil, a demanda também aumenta a olhos vistos graças ao número de estrangeiros que

\footnotetext{
* Universidade de São Paulo
} 
vêm para o país a trabalho ou como estudantes intercambistas. Mesmo em contexto de imersão, muitos desses estrangeiros buscam um aprendizado formal da língua.

O momento, portanto, é bastante favorável para reflexões sobre PLM e PLE, quer porque haja críticas em relação ao ensino - muitos alunos ficam aquém do esperado nas avaliações internas -, quer pelo sentimento auspicioso que cerca a língua portuguesa e a cultura brasileira no exterior.

O fato é que maior demanda pelo aprendizado leva à necessidade de mais professores formados - e bem formados - para atender às exigências do mercado.

Antes de prosseguir, cabe uma observação à terminologia que emprego aqui. Não recorro à distinção entre português segunda língua (PL2), ensinado em situação de imersão, e PLE, aprendido fora do país em que a língua-alvo é também a língua materna dos habitantes. Embora haja distinções consideráveis nesses dois processos - por exemplo, enquanto em PL2 a exposição do aprendiz não é só linguística, mas também cultural, em PLE as possibilidades comunicativas são bem mais reduzidas -, tais diferenciações não interferem nos propósitos deste texto: cotejar o desenvolvimento já alcançado no ensino de PLM e PLE. Dessemelhanças entre o ensino de PL2 para comunidades autóctones (grupos indígenas) ou alóctones (descendentes de imigrantes) também não interferem na análise em foco. PLE, portanto, é entendido aqui como língua não materna, e só não recorro a esse termo em função de a tradição terminológica da área acolher o termo PLE com muita familiaridade.

Com esse objetivo, a estrutura do texto inicialmente analisa os percursos do ensino de PLM, seguido dos caminhos experimentados pelo PLE. Na sequência, verificam-se algumas características gerais do ensino de línguas. Sugestões para o encaminhamento dessas práticas encerram as reflexões.

\section{Ensino de PLM}

Para tentar entender a restrição das aulas de PLM à abordagem da gramática tradicional, lembro que as concepções dessa perspectiva de trabalho adaptam-se muito bem às da linguística do sistema, insistentemente divulgadas até meados dos anos $70 \mathrm{e}$ fundamentadas no Curso de linguística geral (SAUSSURE, 2006), obra póstuma de 1916, compilada por alunos do mestre genebrino.

Buscando satisfazer o critério científico, Saussure vê a língua como objeto uno, homogêneo. A diversidade pertence à fala, ao individual, acessório e acidental. Essa dicotomia saussuriana (langue/parole) leva ao imobilismo do sistema. A língua é vista de forma imanente, e cabe ao linguista buscar as regularidades do sistema. Percebe-se, portanto, que essa linguística idealiza o falante, tal como as prescrições normativas.

O método saussuriano sofreu fortes críticas, como a exposição abaixo ilustra: 
1. nas formas linguísticas, o fator normativo e estável prevalece sobre o caráter mutável;

2. o abstrato prevalece sobre o concreto;

3. o sistemático abstrato prevalece sobre a verdade histórica;

4. as formas dos elementos prevalecem sobre as do conjunto;

5. a reificação do elemento linguístico isolado substitui a dinâmica da fala;

6. univocidade da palavra mais do que polissemia e plurivalência vivas;

7. representação da linguagem como um produto acabado, que se transmite de geração a geração;

8. incapacidade de compreender o processo gerativo interno da língua. (BAKHTIN, 1981, p. 103)

Isso equivale a dizer que a linguística do sistema trabalha a língua como um objeto morto, congelado. Ao considerá-la fora do fluxo sócio-histórico a que de fato pertence, os fatos linguísticos são encarados sem a representatividade ideológica que os liga a essa corrente contínua. Analogamente, seria como se estudássemos a arquitetura apenas pelo levantamento dos traços, tipologia das formas, arranjo estético, apartando dessa morfologia as diferentes relações sociais aí impressas.

Bem diferente do paradigma anterior, a linguística do uso adota a ideia de adequação contextual, ampliando a ótica trabalhada: do sintagma ao texto. Considera-se o contexto e a própria enunciação, alargando as possibilidades de estudo linguístico. Mais do que isso: aproxima-se de uma concepção mais real, menos utopicamente idealizada dos fatos da língua.

[...] a Linguística do Uso/Funcionamento do Sistema apresenta-se como uma Linguística que visa a uma efectiva aproximação aos fenômenos comunicativos - procurando, então, levantar no aparente caos ou na variedade aparentemente inesgotável do exercício discursivo princípios norteadores e regularidades sistematizáveis e propor em consonância com isso uma caracterização adequada da própria estrutura da língua. (FONSECA, 1994, p. 97-98)

Dessa forma, a linguística do funcionamento do sistema estuda os processos de linguagem em uso na vida social. Essa dimensão concreta dos atos de linguagem não poderia ser colocada em plano secundário, como vinha ocorrendo nos estudos da linguística do sistema, privilegiada durante muito tempo na investigação científica.

Enquanto essas teorias linguísticas difundiam-se entre os professores, novas práticas pedagógicas foram sendo criadas para arejar o ensino de PLM. Propagou-se, então, a ideia de que deveria trabalhar-se o texto, unidade mínima de sentido para os linguistas. 
Desprezada a confusão inicial que as teorias linguísticas causaram, não se podem negar algumas mudanças no tratamento dispensado às aulas de PLM. É fato que a pedagogia de PLM não caminha como há trinta anos. Afinal, a partir de 1962, com a introdução das aulas de linguística nos cursos de Letras, o professor não pôde ignorar as novas concepções de língua.

A abordagem a partir dos textos representou, sem dúvida, um avanço considerável no modus faciendi. No entanto, guardadas as ilhas de excelência, o texto continua sendo usado para a classificação morfossintática dos termos, sem nenhuma relação com o co-texto, ou seja, com o contexto verbal. (PARRET, 1988)

O ensino da gramática classificatória ainda polariza as atenções nas aulas de PLM, a despeito de especialistas já terem alertado que "[...] um menino não aprende a língua materna pela definição do adjetivo, substantivo, pronome, como não aprendemos a respirar estudando gravuras de pulmões". (LUFT, 1985, p. 52)

Desde a década de 90, estudiosos vêm mostrando a defasagem entre as pesquisas acadêmicas e as aulas de PLM. Ilari constata que "[...] os usos da língua na escola continuam em grande medida artificiais, como se o aprendizado fosse para a escola, não para a vida”. (1992, p. 103)

Esse descompasso entre as investigações teóricas e as práticas pedagógicas também são perceptíveis nas aulas de PLE.

\section{Ensino de PLE}

Tal como ocorreu com PLM, o ensino de PLE também já vivenciou várias fases, das quais explicito apenas as que tiveram maior impacto na área.

Nos anos 1970, a década da busca pelo melhor método, as estrelas eram o método da gramática e tradução, seguido do audiolingual.

Tendo como ponto de partida a LM, o método da gramática e tradução insiste no aprendizado da produção escrita, sem levar muito em conta a oralidade. A teoria gramatical é usada de forma recorrente nas aulas. O professor explica a estrutura da língua-alvo, utilizando a LM na produção e no processo de comparação, e depois esclarece o sentido, valendo-se da tradução do trecho. No início, o principal é levar o aluno a memorizar palavras. Depois disso, são ensinadas as regras da língua-alvo para a construção das frases e, finalmente, são feitos exercícios de tradução e versão. (LEFFA, 1988)

O audiolingual, fortemente influenciado pelo behaviorismo, foi inicialmente utilizado no treinamento de línguas do exército americano, durante a segunda guerra mundial. Para ampliar rapidamente a fluência dos falantes, as aulas tinham número reduzido de alunos e contava ainda com a contratação de nativos na língua-alvo. As propostas de Skinner e Pavlov são então aplicadas ao ensino de línguas. 
O ensino/aprendizagem de uma língua é assim considerado como um processo mecânico de formação de hábitos com a ajuda de estímulos e de respostas visuais e sonoras (como as frases de um diálogo e as imagens correspondentes em um manual ou tela). Aprender é adquirir uma conduta de reflexo, como faz o cão de Pavlov que saliva ao ouvir a campainha ou o rato que aprende a abrir a armadilha do alimento. (VASSEUR, 2006, p. 86)

Em oposição à abordagem da gramática e tradução, algumas premissas do audiolingual são: "língua é fala, não escrita [...]; língua é um conjunto de hábitos [...]; ensine a língua, não sobre a língua [...]; as línguas são diferentes [...]”. (LEFFA, 1988, p. 12-14)

Embora tenha alcançado sucesso no início, logo os problemas em relação ao audiolingual começaram a surgir: em situações interativas reais, os exaustivos exercícios de repetição feitos em aula paralisavam o aluno, que não conseguia se comunicar.

Os anos 1980, então, deslocaram a ênfase para a língua-alvo e os processos de aquisição, sendo a década de valorização da interação.

Esse breve sumário das teorias de ensino de línguas estrangeiras pode ser consultado com maior detalhamento em Leffa (1988).

Detenho-me aqui no método comunicativo, cujo desenvolvimento seminal acontece com a publicação de Widdowson, em 1978 (2005). Nessa obra, o autor propõe uma guinada em relação à abordagem até então vigente: a proposta é priorizar o sentido.

Uma vez que o nosso objetivo é capacitar o aprendiz a enfrentar o discurso de uma maneira ou de outra, seria razoável recomendar que se partisse do discurso como ponto de referência para todos os exercícios a serem concebidos. Gostaria de propor que as unidades de um curso e as tarefas de ensino que elas especificam fossem organizadas de maneira a favorecer a passagem de um discurso para outro. (WIDDOWSON, 2005, p. 198)

Com esse propósito comunicativo, Widdowson também sugere que se recorra a conteúdo interdisciplinar.

No Brasil, a abordagem comunicativa foi inicialmente anunciada por Almeida Filho, em 1978, em seminário realizado em Florianópolis (ALMEIDA FILHO, 2007). Desde então, muitos estudos têm sido feitos sobre o tema, que ainda faz parte da agenda dos pesquisadores.

Embora seja possível distinguir diferentes abordagens, podem-se resumir as linhas centrais do comunicativismo pela centralização na mensagem, no "uso da línguaalvo e não na aprendizagem de língua enquanto somente forma/estrutura" (TARDIN, 
2007, p. 283). Essa abordagem teve forte estímulo na década de 1970, impulsionada pelos estudos sobre a competência comunicativa do aprendiz e pela descrença na ênfase em atividades excessivamente centradas na forma e em trechos descontextualizados de amostras da língua. No momento inaugural, houve também influência da sociolinguística, que ampliou o horizonte investigativo ao incorporar o contexto sociocultural aos estudos da linguagem.

Destaco aqui particularmente o aspecto humanista que sustenta a abordagem comunicativa desde o início. No Brasil, Paulo Freire (1977) representa por excelência essa visão pedagógica, que defende o respeito à liberdade do educando e coloca-o como o centro do processo de aprendizagem.

Os programas de ensino comunicativo incorporaram filosofias educacionais baseadas na psicologia humanística, cuja finalidade máxima é o desenvolvimento integral do ser humano. Nessa visão, o aluno é responsável pela sua aprendizagem, pela sua capacidade de tomar decisões, pode expressar sentimentos e opiniões sobre suas necessidades e interesses. (TARDIN, 2007, p. 295)

Essa concepção produz um novo arranjo nos papeis do professor e do aluno, pois ensinar PLE, ou qualquer LE, é mais do que informar sobre o funcionamento da língua: é educar para abrir novos horizontes culturais para o aprendiz, é possibilitar-lhe caminhar na nova cultura com menos estranhamento e mais conforto.

Tal como se verificou em relação a PLM, a sala de aula de PLE também não incorporou os avanços teóricos da área. "Ao longo da história tem sido forte a tendência de promover o 'estudo' formal de aspectos sistêmicos da língua-alvo vestidos com roupagem situacional em diálogos e reconhecíveis em pequenos textos." (ALMEIDA FILHO, 2007, p. 66)

Mesmo após a divulgação de abordagens com maior crédito entre os especialistas, em eventos acadêmicos e em cursos de formação de professores, as aulas de PLE permanecem concentradas na estrutura da língua-meta. Doses homeopáticas de interação costumam iludir o professor, que afirma categoricamente que utiliza a abordagem comunicativa.

O preenchimento da disciplina Língua (portuguesa ou estrangeira e, por extensão, o PLE) com gramática como sua matéria por excelência está vivo e endêmico ainda hoje, embora com menor confiança pedagógica, no ensino regular fundamental e médio das escolas do país. A tradição forte, medular, da centralidade da gramática não nos deixará tão cedo, para conforto dos gramaticalistas de todos os matizes e inquietação dos comunicativistas, textualistas e sócio-interacionistas que gostariam de ver o proscênio do ensino ocupado pela construção livre do sentido que já possa ser circulado entre os aprendizes de limitada capacidade de compreensão da nova língua "estudada". (ALMEIDA FILHO, 2007a, p. 39-40) 
Observações pontuais sobre língua materna (LM) e língua estrangeira (LE) também ajudam a caracterizar singularidades do ensino de português a nativos e estrangeiros.

\section{Ensino de Línguas}

Ao cotejar o ensino de LM com o de LE, é possível encontrar diferenças e similaridades nos procedimentos metodológicos e nas práticas pedagógicas, de forma que o PLE pode beneficiar-se, em parte, das investigações realizadas no PLM e viceversa.

Acerca das diferenças, as situações de aquisição e aprendizado aparecem em primeiro plano. No caso da LM, trata-se de um contexto natural, movido pela necessidade e pelo desejo de se comunicar, o que acelera a aquisição. Em relação à LE, em situação formal, a artificialidade decorre de não ser questão de sobrevivência, o que evidencia a relação cognitiva do aprendizado: o adulto infere regras da língua-alvo a partir da comparação com as estruturas que conhece da LM e quase sempre busca explicações metalinguísticas para os fenômenos da língua.

Outro ponto divergente refere-se ao repertório cultural. Na LM estamos literalmente em casa. Inseridos na cultura e na sutileza de seus imperativos, somos conhecedores natos do que se aprova e do que se rechaça. Na LE, o estranhamento, seguido muitas vezes de desconforto, é a sensação inicial decorrente das diferentes formas de interpretar o mundo, pois "[...] no contato com a segunda língua já estamos constituídos como sujeitos, já estamos inseridos em uma língua e uma cultura que formataram nossa forma de nos relacionarmos com nós mesmos, com o outro e com o mundo". (SANTOS, 2005, p. 45)

Littlewood (2006), ao investigar a LE, analisa primeiramente a aquisição de LM e encontra similaridades nos dois processos.

Often, our increased knowledge of first language acquisition has served as a backcloth for perceiving and understanding new facts about second language learning. In addition, many researches see their long-term goal as to produce a single "theory of language acquisition", which would account for first and second language learning within one framework. After all, the two experiences are both manifestations of the general human capacity to learn and use language. (p. 4)

Outra aproximação diz respeito à familiaridade com a própria $L M$, o que depende do repertório linguístico de cada usuário: quem transita com mais facilidade 
pelos diferentes registros e gêneros da LM aprende outra língua com mais desembaraço. A questão etária também já foi analisada:

[...] a aquisição do léxico e a capacidade de planejar o discurso numa segunda língua podem ser facilitadas com a maturidade, através de estratégias metalinguísticas conscientes que se concentrem nos procedimentos depois transferidos para o uso da língua. Para essas habilidades, então, quanto maior for o domínio linguístico na língua nativa, tanto mais facilitado o caminho para a proficiência nas segundas línguas nessas habilidades. (VENTURI, 2006, p. 124)

A influência da LM no aprendizado de LE pode ser tão grande a ponto de levar à hipergeneralização de regras, quando o aprendente espera encontrar na língua-alvo a mesma estrutura da LM.

Embora seja possível encontrar similaridades entre o ensino de PLM e PLE, estudiosos afirmam que o professor de PLM deve complementar a formação para atuar em PLE (ALMEIDA FILHO, CUNHA, 2007). Penso que a recíproca seja verdadeira: o professor de PLE também deve especializar-se para atuar em PLM, dadas as necessidades específicas de ensino instrumental.

Precisamente no tocante à formação de professores de PLE, várias pesquisas registram o cenário presente e o desejável (ALMEIDA FILHO, 2009; ABRAHÃO, 2009; BLATYTA, 2009; FONSECA, 2009). Esses estudos já demonstraram que ensinar PLE difere de ensinar PLM, quer nas teorias, quer nas práticas de sala de aula. Em ambos os casos, a linguística aplicada tem contribuído com a ampliação de propostas.

\begin{abstract}
A área de EPLE é o aglomerado de manifestações do e pelo ensino de português como uma nova língua para falantes de outros idiomas, mais as iniciativas de reflexões sobre o estudo do processo de ensinar e aprender português nessa condição de estrangeiridade, e as providências e produtos de profissionalização para que se realize e aperfeiçoe o referido processo. (ALMEIDA FILHO, 2007b, p. 34)
\end{abstract}

Além disso, a licenciatura dos cursos de Letras, que certifica o professor de língua, aborda a formação básica na prática de ensino e estágio supervisionado nas línguas estudadas (português, inglês, francês, alemão, espanhol, etc.), mas ainda não inclui PLE em seu programa. Os poucos cursos existentes para a preparação de professores de PLE (ALMEIDA FILHO, 2007a) confirmam o fosso na institucionalização dessa área. Essa situação, vigente na maioria das IES, corrobora para que o ensino de PLE mantenha-se num plano amador, intuitivo, menos profissionalizado.

Como ficou demonstrado, o ensino de LM e LE não são dimensões estanques e incomunicáveis. Há pontos de contato, por exemplo, o fato de que "o ensino de 
qualquer língua, estrangeira ou materna, deve visar a objetivos comunicacionais e emancipatórios". (ROCHA, 2007, p. 72)

Outra proximidade entre ambos é o aproveitamento das concepções da Pragmática no ensino. Tanto na linguística do uso (analisada acima em relação a PLM) quanto na abordagem comunicativa (utilizada no PLE), a influência positiva das teorias pragmáticas é notória, pois levam-se em conta as intenções comunicativas do falante nos diversos eventos comunicativos.

Dessa forma, as pesquisas acadêmicas demonstram melhorias nas propostas para o ensino de línguas - materna e estrangeira. No entanto, parece haver um entrave que impossibilita o salto qualitativo necessário para que esse conhecimento seja transformado em ação.

Como solucionar esse problema?

Conclusão

No ensino de PLM e PLE, o desvelo tem ficado mais no âmbito das investigações teóricas, ainda com pouca ressonância na prática pedagógica, porque o professor, muitas vezes deslocado do ambiente acadêmico, não atribui valor às recomendações dos especialistas. Influenciado por seu sistema de crenças, recorre às suas motivações internas quando se depara com os alunos. (BARCELOS, ABRAHÃO, 2006)

É por esse motivo que os cursos de formação continuada devem fazer parte da política de profissionalização do ensino de língua. Isso significa que os gestores educacionais devem ser generosos na promoção de cursos para professores que já atuam no mercado.

Além disso, os cursos de Letras precisam arejar seus programas, de forma a garantir um conteúdo mais diversificado e atualizado para aqueles que estão em formação. Já existem propostas pioneiras, por exemplo, a inclusão da disciplina "Empreendorismo", na qual os alunos têm "a oportunidade de definir sua missão pessoal, seus objetivos e metas e de traçar planos para conquistá-las, avaliando seu conhecimento real, sua rede de contatos, sua bagagem vivencial, suas ações curriculares e extracurriculares e suas necessidades de aprendizagem". (AMARAL, 2005, p. 154)

Com alicerce teórico reforçado, é mais provável que o professor sinta-se confiante em fazer opções mais adequadas à realidade com que lida em aula e mais condizentes às suas crenças.

Por outro lado, acredito que o investimento não deva ser apenas na capacitação técnica. Ocorre que as mudanças sociais mais recentes ainda não foram incorporadas pela instituição escolar. 
O modelo anterior de educação pregava um professor centralizador e profundo conhecedor de teorias estáveis. Sua (pseudo) onisciência garantia-lhe situação monologal nas aulas: ele era o dono da voz, o senhor a que os alunos deviam submissão. Tolhido da condição básica essencial ao ser humano - a capacidade de pensar livremente, "a sua ontológica vocação de ser sujeito" (FREIRE, 1977, p. 36) -, restava ao aprendiz acompanhar passivamente as exposições monocórdias da autoridade professoral, anotar e depois repeti-las nos exercícios e nas provas.

Ora, é fácil perceber que esse paradigma de educação não se sustenta mais na atualidade, não só porque os conteúdos são instáveis e facilmente recuperados (e alterados) por meio da tecnologia, mas também porque as mudanças sociais promoveram profundas alterações nas relações pessoais e profissionais. Trabalhos em equipe são valorizados, dada a importância cada vez maior de se aprender a lidar com as diferenças. O foco pedagógico hoje está na compreensão e não na memorização. Desse aprendizado dialogal e ativo, objetiva-se aprimorar a capacidade crítica e a reflexão autônoma do aprendiz.

As modificações são profundas, mas têm permanecido restritas aos estudos dos especialistas educacionais, sem adentrar a sala de aula. O problema, incômodo e indelével, é o fato de que muitas aulas ainda se estruturam pelo primeiro modelo acima, completamente distanciado da sociedade igualitária que precisamos construir.

A acomodação ao paradigma mais apartado da modernidade invade todas as disciplinas, produzindo resultados nefastos. Isso prova que a crise não está restrita ao ensino de línguas: o que temos de enfrentar é uma crise da instituição escolar, anunciada há tempo. (TEIXEIRA, 2006; SOARES, 1996)

Nas aulas de PLM, isso se traduz na manutenção do ensino gramaticalista que tanto arrelia os aprendizes e cujo efeito mais devastador é levá-lo a entender que ensino de PLM é classificação morfossintática de termos e orações, daí resultando um declarado ódio à língua.

No ensino de PLE, a concentração na forma também deixa de valorizar aspectos culturais inalienáveis no aprendizado de outra língua, limitando a atuação do aprendiz na comunidade-alvo, restringindo a formação da cidadania e diluindo a posição de destaque que o conhecimento de uma nova língua/cultura representa na sociedade global.

Como alterar esse estado de coisas? Essa realidade não se resolve criticando o professor, que já enfrenta tantos percalços no exercício da profissão, do parco salário à falta de estrutura das instituições, somados ao descaso dos gestores. Aliás, vale lembrar que o professor fundamenta as suas aulas na formação que recebeu, quase sempre sustentada no primeiro paradigma exposto acima.

Entendo que alguns posicionamentos dependem dos gestores que ocupam o topo da política educacional. Faltam ações que integrem a classe de professores e institucionalizem objetivos e procedimentos educacionais. Faltam atitudes claras que revitalizem a profissão e que façam com que os professores sejam vistos como importantes na sociedade do conhecimento. 
As instituições escolares também deveriam exercer a função que lhes cabe, no mínimo melhorando o capital estrutural, ou seja, a infraestrutura. Em muitas escolas, por exemplo, as salas de PLE não contam com o equipamento básico para o ensino: não há laboratório de línguas, nem televisor e vídeo, tampouco gravador. Cabe à boa vontade do professor a aquisição dessas ferramentas, úteis no método sócio-interativo. Note-se que sequer mencionei tecnologias atuais - salas equipadas com computador conectado à internet e com tela de projeção para visualização de todos os presentes. Isso permitiria utilizar farto material disponível na internet - conectar-se ao mundo, enfim.

Devem-se construir redes de colaboração entre professores e pesquisadores, nas quais ambos tenham participação ativa. Isso significa que os professores não ficarão apenas ouvindo os pesquisadores sugerirem o que deve ser feito, mas devem contribuir com a experiência acumulada em sala de aula. Um bom começo seria um espaço reservado em eventos científicos para a apresentação de trabalhos de professores atuantes no ensino fundamental e médio, e professores autônomos de PLE, mesmo que afastados da pós-graduação (ou sobretudo esses). Ouvindo-os, os pesquisadores poderíamos aprender muito sobre a realidade pedagógica com a qual as teorias estudadas buscam colaborar. Trata-se, portanto, de uma nova orientação para a maneira como estruturamos a pesquisa.

É fácil notar que as mudanças requeridas pouco dependem de ações individuais. Devem, sim, ser sincronizadas pelos que representam a categoria na alçada governamental. Como microcosmo da sociedade, a realidade educacional muda quando os valores atribuídos à educação são transformados. $\mathrm{O}$ investimento no capital humano, assim, será feito quando se valorizar a profissão de professor como elemento fundamental para o desenvolvimento do país.

\section{Referências Bibliográficas}

ABRAHÃO, Maria Helena V. Tentativas de construção de uma prática renovada: a formação em serviço em questão. In: ALMEIDA FILHO, José C. P. de (Org.). $O$ professor de língua estrangeira em formação. 3. ed. Campinas: Pontes, 2009. p. 29-50.

ALMEIDA FILHO, José C. P. de. Análise de abordagem como procedimento fundador de autoconhecimento e mudança para o professor de língua estrangeira. In: ALMEIDA FILHO, José C. P. de. (Org.) O professor de língua estrangeira em formação. 3. ed. Campinas: Pontes, 2009. p. 11-28.

. Linguística aplicada - ensino de línguas e comunicação. 2. ed. Campinas: Pontes, ArteLíngua, 2007.

. Índices nacionais de desenvolvimento do ensino de português língua estrangeira. In: ALMEIDA FILHO, José C. P. de; CUNHA, Maria Jandyra C. Projetos iniciais em português para falantes de outras línguas. Brasília/Campinas: UnB/Pontes, 2007a. p. 39-55.

. Maneiras de credenciar-se na área de ensino de português a falantes de outras línguas. In: ALMEIDA FILHO, José C. P. de; CUNHA, Maria Jandyra C. Projetos 
iniciais em português para falantes de outras línguas. Brasília/Campinas: UnB/Pontes, 2007b. p. 33-37.

AMARAL, Vera L. do Vamos começar do fim? In: BRUNO, Fátima C. (Org.) Ensinoaprendizagem de línguas estrangeiras: reflexão e prática. São Carlos: Claraluz, 2005. p. 145-157.

BAKHTIN, Mikhail. Marxismo e filosofia da linguagem. Tradução de Michel Lahud e Yara F. Vieira. São Paulo: Hucitec, 1981.

BARCElOS, Ana M. F.; ABRAHÃO, Maria Helena V. (Orgs.) Crenças e ensino de línguas - foco no professor, no aluno e na formação de professores. Campinas: Pontes, 2006.

BLATYTA, Dora F. Mudança de habitus e teorias implícitas - uma relação dialógica no processo de educação continuada de professores. In: ALMEIDA FILHO, José C. P. de (Org.). O professor de língua estrangeira em formação. 3. ed. Campinas: Pontes, 2009. p. $63-82$.

FONSECA, Joaquim. Pragmática linguística: introdução, teoria e descrição do português. Porto: Porto, 1994.

FONSECA, Maria Ruth F. S. T. Prática e teoria na (trans)formação de professores de língua estrangeira. In: ALMEIDA FILHO, José C. P. de (Org.). O professor de língua estrangeira em formação. 3. ed. Campinas: Pontes, 2009. p. 83-92.

FREIRE, Paulo. Educação como prática de liberdade. 7. ed. Rio de Janeiro: Paz e Terra, 1977.

ILARI, Rodolfo. A linguística e o ensino da língua portuguesa. 4. ed. São Paulo: Martins Fontes, 1992.

LEFFA, Vilson J. Metodologia do ensino de línguas. 1988. In http://www.leffa.pro.br/textos/trabalhos/Metodologia_ensino_linguas.pdf. Acesso em 1. abril 2010, $16 \mathrm{~h} 51$.

LITTLEWOOD, William T. Foreign and second language learning. $20^{\text {th }}$ printing. Cambridge: Cambridge University Press, 2006.

LUFT, Celso P. Língua e liberdade: por uma nova concepção da língua materna e seu ensino. Porto Alegre: LP\&M, 1985.

PARRET, Herman. O objetivo e o domínio da pragmática. In: Enunciação e pragmática. Tradução de Eni Orlandi et alii. Campinas: Unicamp, 1988. p. 15-21.

ROCHA, Cláudia H. Reflexões e proposições sobre o ensino de LE para crianças no contexto educacional brasileiro. In: ALVAREZ, Maria Luisa O.; SILVA, Kleber A. da (Orgs.) Linguística aplicada: múltiplos olhares. Brasília/Campinas: UnB, Finatec/Pontes, 2007. p. 71-107. 
SANTOS, Hélade S. O "erro" do aluno de língua estrangeira sob um outro olhar. In: BRUNO, Fátima C. (Org.) Ensino-aprendizagem de línguas estrangeiras: reflexão $e$ prática. São Carlos: Claraluz, 2005. p. 37-52.

SAUSSURE, Ferdinand de. Curso de linguística geral. Tradução de Antônio Chelini, José Paulo Paes e Izidoro Blikstein. 27. ed. São Paulo: Cultrix, 2006.

SOARES, Magda. Linguagem e escola: uma perspectiva social. 14. ed. São Paulo: Ática, 1996.

TARDIN, Rita de C. Das origens do comunicativismo. In: ALVAREZ, Maria Luisa O.; SILVA, Kleber A. da (Orgs.) Linguística aplicada: múltiplos olhares. Brasília/Campinas: UnB, Finatec/Pontes, 2007. p. 281-301.

TEIXEIRA, Anísio. Educação e o mundo moderno. Rio de Janeiro: UFRJ, 2006.

VASSEUR, Marie-Thérèse. Aquisição da L2: compreender como se aprende para compreender o desenvolvimento da competência em interagir em L2. In: DEL RÉ, Alessandra. (Org.) Aquisição da linguagem: uma abordagem psicolinguística. São Paulo: Contexto, 2006. p. 85-111.

VENTURI, Maria Alice. Aquisição de língua estrangeira numa perspectiva de estudos aplicados. In: DEL RÉ, Alessandra. (Org.) Aquisição da linguagem: uma abordagem psicolinguística. São Paulo: Contexto, 2006. p. 113-134.

WIDDOWSON, Henry G. O ensino de línguas para a comunicação. Tradução de José C. P. de Almeida Filho. 2. ed. Campinas: Pontes, 2005.

Abstract: This paper shows different methods used in the Portuguese language teaching for both native and foreign speakers, searching for connections between them. This methodological approach emphasizes conceptions related to the system and the language use, as well as it explains some methods: grammar translation, audio-lingual and, with more detail, the communicative approach. The analysis of these ways of teaching reveals that the grammar approach is still mostly used in classes, despite the fact that the theoretical researches have already questioned this approach. After considering why the results of researches have little employment in classrooms, ways of reducing the distance between the theoretical studies and the pedagogical practice are presented.

Key words: Portuguese language; mother tongue; foreign language; teaching 